\title{
Filling the gaps: shaping lighting. Education for the future
}

\author{
P. Bech-Larsen ${ }^{1}$, S. Linnebjerg ${ }^{l}$ and M.F. Mullins ${ }^{1}$ \\ ${ }^{1}$ Aalborg University, Copenhagen, Denmark \\ pbl@create.aau.dksl@create.aau.dk mullins@create.aau.dk
}

\begin{abstract}
Training and knowledge of lighting is an increasingly sought-after professional quality in Denmark and Sweden. However, technological development in the lighting field has been in recent years extremely rapid, not least in Scandinavia. This has led to a situation, where users, designers, specifiers, buyers and installers are often neither in possession, nor have access to, the knowledge about lighting that they need. The aim of the study is to map and analyze the existing offer and demand for competencies within lighting related fields. That is to say, the study has looked at the existing educational programs within a broad field of lighting and compared this 'supply' to the current 'demand' by local employers. The paper presents the results from a statistical analysis of data collected from a series of surveys, expert interviews and focus groups, involving more than 250 participants in Sweden and Denmark. Based on the findings, the paper presents recommendations for the design of educational curricula.
\end{abstract}

\section{Introduction}

Light has been shown to have a significant impact on our daily lives in such fields as health, learning, work and general wellbeing (Schlangen et al., 2014). Training and knowledge of lighting is therefore becoming a more widely sought professional quality in Denmark and Sweden. However, technological development in the lighting field has in recent years been extremely rapid, not least in Scandinavia. This has led to a situation, where users, designers, specifiers, buyers and installers have in many cases been outpaced and are neither in possession nor have access to the knowledge about lighting that they need. For example, latest LED developments entail completely new prerequisites for electricians, electrical installers, architects, urban planners and municipalities. Another example is that IT educational programs should today include the development of programming skills that are required by 'intelligent' lighting. For the purpose of this study, these bottlenecks are referred to the 'gaps' between the existing educational offer and industry's demand.

The quantifying and mapping of the supply and demand for lighting-related competencies in Denmark and Sweden provides the basis for the investigation of the current gaps. The study has investigated the relation between the demand, driven by the labor market, and the educational offer within the 
interdisciplinary field of lighting, through a series of extensive surveys that helped collect data on the current situation in Greater Copenhagen.

The aim of the study was to map and analyze the present offer and demand for competencies within lighting related fields. That is to say, the study looked at the existing educational programs within a broad field of lighting and compared this 'supply' to the current 'demand' by local employers.

The research identifies and contributes to the establishment and growth of underdeveloped or lacking competencies in the region. This approach attempts to lay the foundation for a comprehensive strategy for reducing the 'gap' between labor demand and the provision of educational services in the lighting field. Mapping the existing competencies can also strengthen and expand lighting education in the region by opening up new possibilities for collaboration between municipalities, industry and educational institutions. Establishing future scenarios within this context can pave the way for new beneficial partnerships with the aim to improve their international competitiveness. Building a strong relation between educators and employers in the region can be beneficial for all parties, including municipalities, private companies as well as educational institutions themselves. The field of lighting is rapidly developing and expanding to include an increasing number of disciplines varying from technical and humanistic to artistic practices both on a practical and theoretical level. The goal of the study is therefore to provide an overview to support the development of a comprehensive strategy that reflects the labor market demand, together with the design and organization of the supply-side of the lighting education. The purpose is thus to ensure that well-trained lighting professionals graduate from the educational programs that support the interdisciplinary lighting industry in Greater Copenhagen.

\section{Method}

\subsection{Surveys}

To define the primary themes for this research project, a broad range of competencies were identified within the field of lighting. To validate these competencies and categories, a focus group with selected participants was presented with an initial definition, and the competencies and categories were developed based on the focus group discussion. The results were compared with the previous findings obtained from LYSNET.dk and the "key topics" identified in the DCL report (Dansk Center for Lys \& Innovationsnetværket Dansk Lys, 2012). The final set included 111 competencies and 8 categories. Next, the extensive screening of educational programs in Denmark and Sweden was carried out to identify which programs potentially offer relevant lighting related courses. The analysed educational institutions included universities, university colleges, architectural schools, engineering colleges, stage and art schools, Swedish Högskolar, as well as professional bachelor programs, including those that train electricians.

Relevant search-words were identified and a comprehensive online search was performed for each of the competencies. Based on the findings from UddannelsesGuiden (www.ug.dk), studere.nu and studentum.se, almost 300 educational programs were found to be potentially relevant to the 111 competencies; of these 150 were included in the survey, based on a fine-meshed screening. Online surveys were designed using SurveyXact for all 111 competencies, divided into eight topics. The questions employed a Likert scale to determine the degree to which the included educational programs "supply" the 111 competencies. The questionnaire was tested with 15 selected participants to identify errors. In January 2017, 152 respondents from different educational programs were contacted by phone before the launch of the survey in order to encourage and motivate participation. The selection of this group was based on a spread of the different professionals (within groups such as architecture, engineering, technical etc.); different types of educational programs; and the extent to which the educational institutions were estimated to provide lighting-related competencies. The 'supply' survey was completed and distributed by early 
February 2017. All respondents were sent two reminders and 84 valid responses were received. Subsequently, a similar online survey was designed to establish the 'demand' for the 111 competencies by companies and municipalities. Relevant contact persons were identified via industry related websites and Danish and Swedish light associations, such as: Innovationsnetværk Dansk Lys (DK), Elforsk (DK), Lysnet. dk (DK), Sydljus (SE), Ljuskultur (SE), Belysningsbrachen (SE) and Lighting Metropolis (DK + $\mathrm{SE}$ ). The survey was also advertised in the newsletters for members of DCL (Dansk Center for Lys, DK) and Sydljus (SE). Personal email addresses were gathered online and all demand-participants received the survey by email, with an introduction to the project via SurveyXact. A few random people received a phone call or a personal email. This effort resulted in the database of 435 contact persons and 92 valid answers.

\subsection{Analysis}

Data obtained from the 'supply' survey were subjected to a descriptive analysis. Subsequently, the data obtained from the 'demand' surveys were also analyzed by descriptive analysis. The results of the two initial survey analyses were then compared and major gaps between the supply and demand of the identified competences were identified. Next, Wilcoxon Signed-Rank statistical tests were carried out on the survey results, where the 'supply' answers were paired with the 'demand' answers. This nonparametric test is suitable for paired samples and is based on the ranks of the absolute difference in the values of each pair of Likert scale responses. The findings of the initial descriptive analysis were generally supported by the statistical methods.

To validate the results of the statistically significant gaps and the future possibilities of research, education and collaboration, we interviewed 17 prominent European experts in lighting. Interviews were partially transcribed, highlighting only relevant parts of the interviews. The quantitative results of the current situation in Denmark and Sweden, combined with the qualitative findings from the expert interviews, resulted in several hypotheses formulated for the current situation, the immediate future and for a 5-10 year perspective.

In June 2017, 14 representatives of industry, municipalities and educational institutions from Denmark and Sweden met at Aalborg University in Copenhagen to take part in two focus groups. The results obtained from the surveys, as well as other findings and the preliminary hypotheses formulated based on the series of expert interviews were presented to the participants of these two focus groups. The final analysis was carried out to review the new information, reflect the feedback from the focus groups' perspectives in the findings, and rank and recommend the competencies that require higher education support in the future.

\section{RESULTS}

\subsection{Supply}

In total, 160 respondents were contacted, of which $51 \%$ completed the survey, $5 \%$ partially completed the survey, $4 \%$ were discarded and $40 \%$ did not respond to the questionnaire. As a result, 84 valid answers were obtained from various higher education institutions in Scandinavia, including those offering master studies $(52 \%)$, bachelor studies $(18 \%)$, professional bachelor studies $(6 \%)$, professions $(17 \%)$ and others $(7 \%)$. For the completed and partially completed responses, the country and gender distribution was as follows: Danish (63\%) and Swedish (37\%); female (22\%) and male (78\%) (Figure 1). 


\subsection{Demand}

In total, 435 respondents were contacted, of which $18 \%$ completed the survey, $6 \%$ partially completed the survey, $3 \%$ were discarded and $72 \%$ did not respond to the questionnaire. As a result, 92 valid answers were obtained from industry, including architects (10\%), building consultants $(4 \%)$, consulting engineers $(11 \%)$, daylight advisers $(5 \%)$, from the energy sector (7\%), lighting designers $(21 \%)$, manufacturers $(14 \%)$, municipalities $(11 \%)$, sales $(1 \%)$ and others $(16 \%)$. For the completed and partially completed responses, the country and gender distribution was as follows: Danish (63\%) and Swedish (37\%); female $(25 \%)$ and male (75\%) (Figure 1).

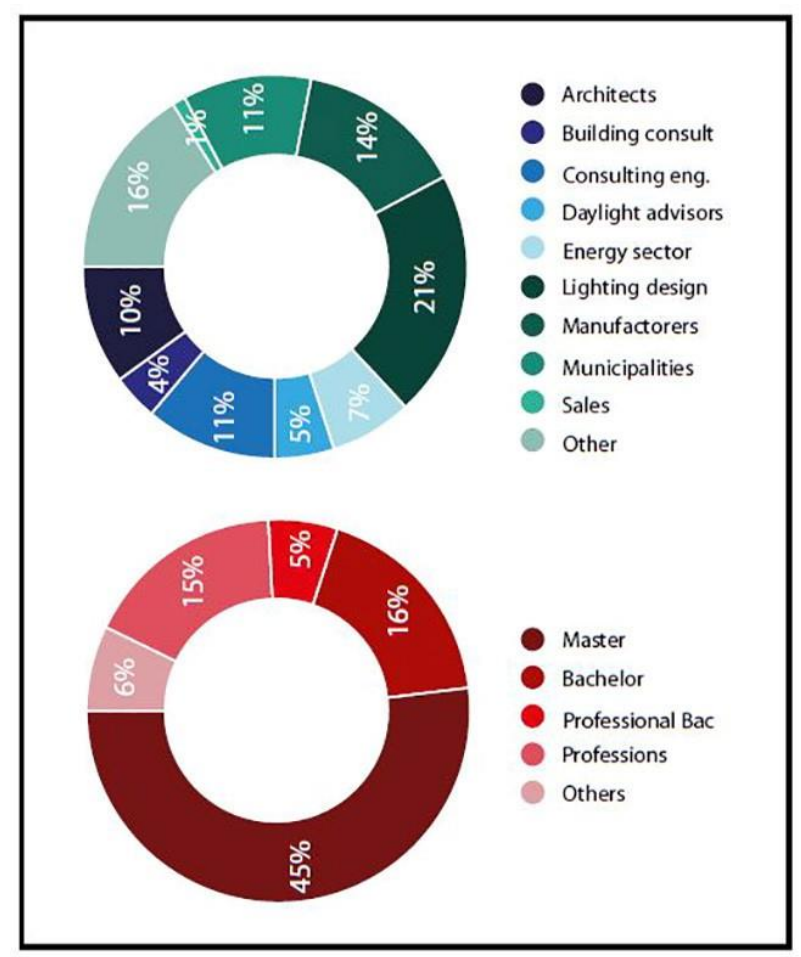

Figure 1: Survey responses based on educational level and sector

\subsection{Crossing borders}

To show the distribution of supply and demand, the survey participants were marked in red and blue, respectively, on the map of Denmark and Southern Sweden (Figure 2). Due to the size difference, five educational institutions in the northern part of Sweden, including two education institutions in Luleå, two in Umeå 2 and one in Sundsvall were not included in Figure 2. The graph shows that the concentration of lighting related competencies is currently highest in the larger cities, particularly in Greater Copenhagen. 


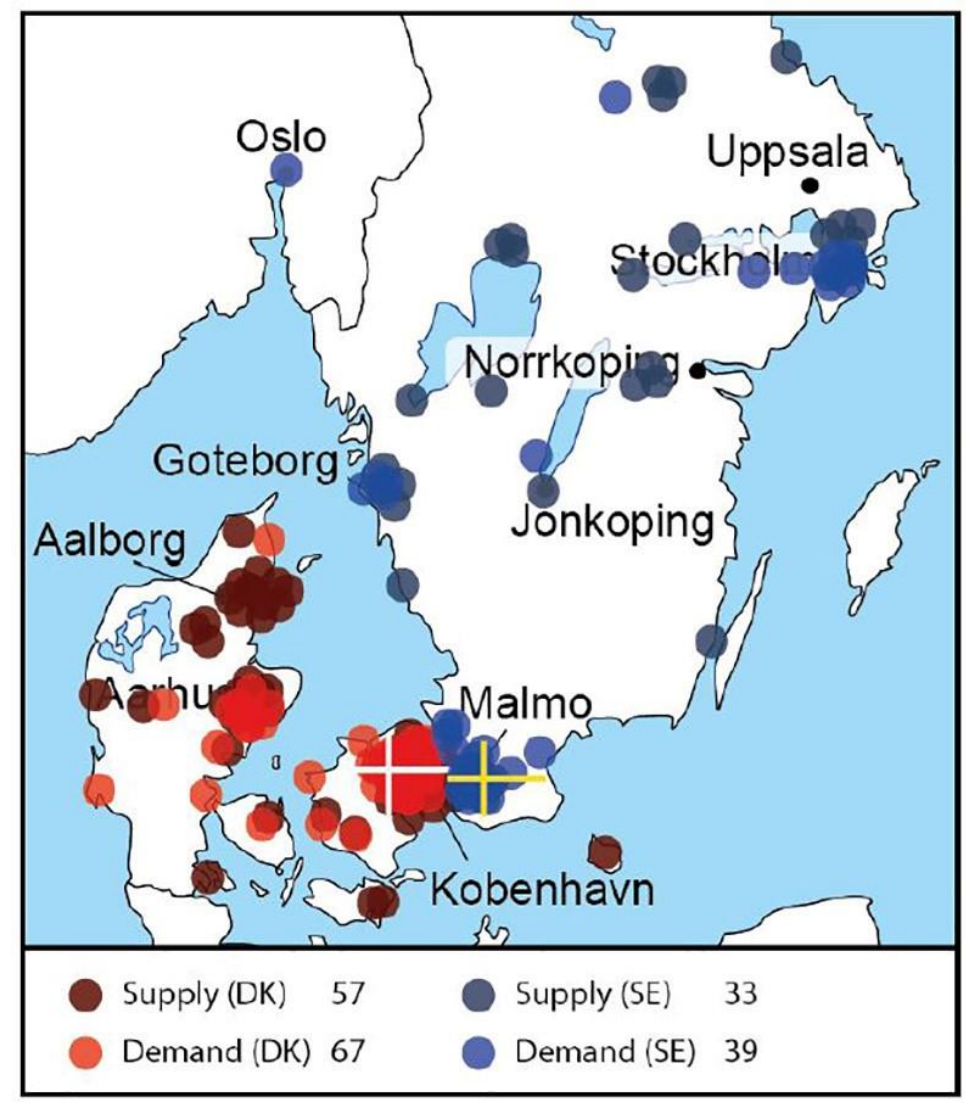

Figure 2: Geographic distribution of survey participants, divided into supply and demand. Red dots representing Danish answers and blue dots

\subsection{Gaps - statistics}

The results of the two online surveys are derived from the survey data and based on a Likert scale of 1-4, where $1=$ not at all, $2=$ to lesser degree, $3=$ to some degree and $4=$ to high degree. The additional option was provided to select "don't know" and add a qualitative comment. The "don't know" answers were discarded. All 111 categories included in the survey were investigated and the biggest gaps were identified and categorized by using descriptive analysis. To investigate these findings more thoroughly, we applied statistical analysis in the form of a Wilcoxon Signed-Rank test. Statistical significance supported the indication for the effect of the gaps, thereby, ensuring reliability of the obtained results and supporting the final categorization of the identified gaps between supply and demand. 


\subsection{Overview of competencies and categories}

All results were compiled in a table (only partially reproduced in Figure 3) by combining all the information to provide an overview of all competencies and categories.

The first column of the table refers to the category of priority. Selected competencies were categorized with pink (high priority), orange (some priority), yellow (less priority) and white (no priority).

The second column indicates the characteristic of the gap: ' $d$ ' means the gap is large because the demand is very high (average $>3$ ), ' $\mathrm{s}$ ' is used when the supply is very low (average $<2$ ) and " $\mathrm{d} / \mathrm{s}$ " is used when a competence has both a high demand and a low supply.

The third and fourth columns show a color code based on the average S (supply) and D (demand). Bright red (lowest $<1.5$ ) - yellow (average 2.25-2.5) - highest (dark blue $>3.45$ ) (Table 1, 2 of 2 for the entire scale).

The fifth column indicates how large the gap between the averages of supply and demand is. Green $=$ good $<0.75$; white $=$ okay $0.76-0.90$; blue $=$ not good; $0.91-1.24$; pink $=$ alarming $>1.25$.

The next three columns show the findings of the statistical Wilcoxon ranked sum analysis. More red dots (1-3) equal bigger statistical evidence of the gap. (1) If Effect Size $>0.3$ and either mean or mode have a measureable difference $>2$. (2) If the last test is true $=$ if effect size $>0.3$ and supported by two measures $=$ the difference in both mean and mode $>2$. (3) If the last test $=$ true, supported by the two measures and effect size $>0.5$.

The ninth and tenth columns refer to the name and number of the topics and competencies.

The columns eleven to thirteen rank the three educational levels with the highest supply in that category and the column fourteen the most frequent number in that topic.

The same applies to the columns seventeen to twenty, where the numbers refer to the sector with the highest demand. If the numbers are red, the supply/demand is very low all over. If the numbers are green, the demand is very high for all categories and maybe in more than three.

The last two columns, fifteen and sixteen, refer to the above-mentioned educational scores, but are related to the nationality, where red represents Denmark (DK) and blue represents Sweden (SE). A darker color shows that the supply/demand is convincingly higher in either DK or SE, while if the color is light, the supply/demand is higher, but not to the same degree. 


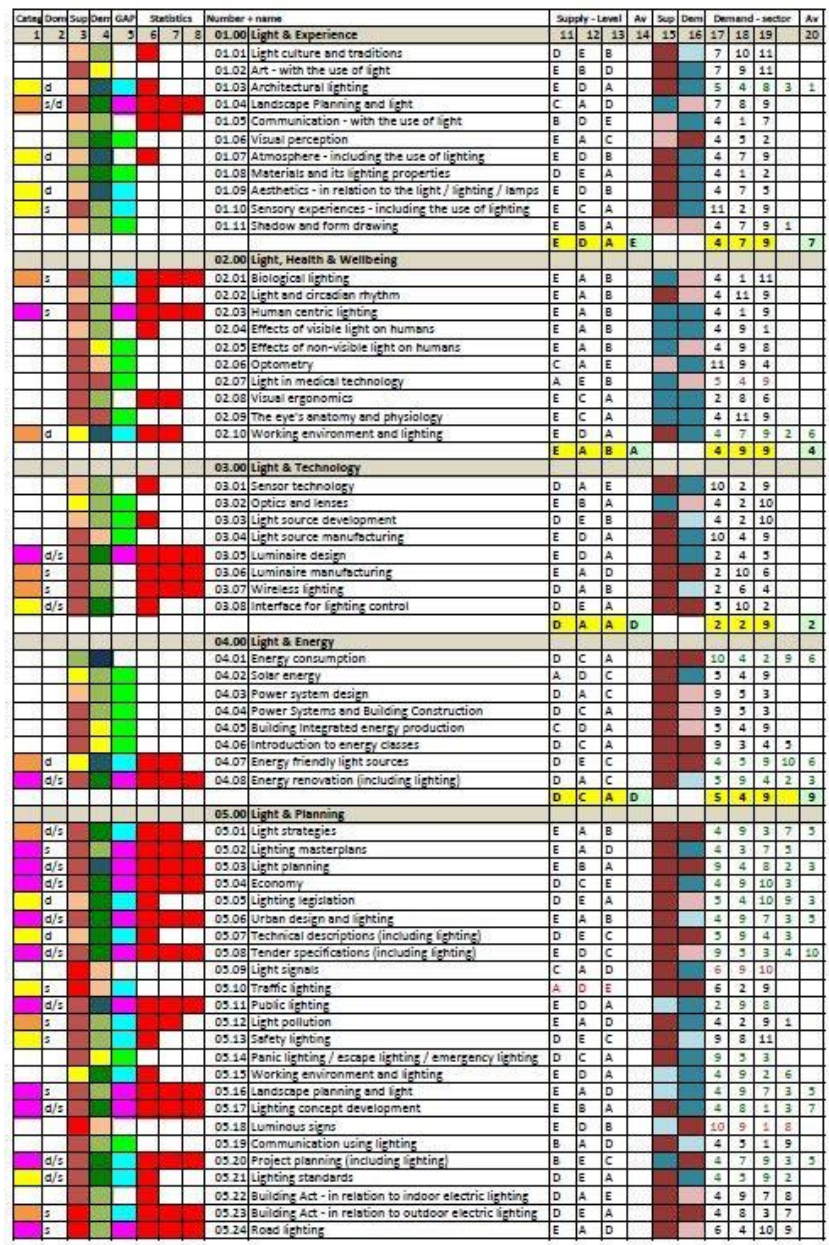

Figure 3: Comprehensive overview of analysis results (only partially reproduced here)

\section{DISCUSSION}

\subsection{Pros and cons}

Mapping the gaps between the educational supply on the one hand, and the demand from the interdisciplinary lighting industry, on the other, in both Denmark and Sweden proved to be very complex. Therefore, several decisions were made to both define and limit the study. These include a more precise definition of the employers (municipalities and industries) located in the Greater Copenhagen Region, while educational programs covered the entire area of Denmark and Sweden. This decision was made early in the study, considering the fact that employers do not necessarily rely on local education providers to obtain the knowledge they require. However, it may be argued that the education programs referred to in the study might be developed in the region with advantages to both education and employers. This 
discussion however goes beyond the scope of this study and remains within the remit of the overall Lighting Metropolis strategy.

Furthermore, the selection of the Likert Scale for collecting quantitative data proved to have both benefits and disadvantages. One of the benefits was the possibility to combine all 111 competencies into one questionnaire suitable for various types of respondents. This open approach allowed us to combine, within an almost identical questionnaire, various educational levels, institutions, courses, and systems into one group of respondents. It has also enabled us to combine a wide variety and size of "demanders" in the private and public sector, including municipalities, artists, international engineering companies, architect firms, salesmen and lighting designers, into the second group of respondents. In this way, the survey could embrace different types of respondents and accommodate the variety to be found in the context of the study.

Reaching a minimum of 80 participants from both groups was set as the target. While this target was in fact achieved, the supply-survey response rate was $51 \%$, which despite personal phone calls and email correspondence was lower than the goal of $70 \%$ of the invited participants. This result may have been influenced by the inclusion of a long introduction text and 111 questions, some of which had little or no relevance for some respondents. Additional bias may have occurred because some relevant educational institutions did not participate in the study.

The Likert scale applied for the survey questions included the following measures, namely "high degree", "some degree", "lesser degree" and "not at all". To some degree, the respondents answered based on their subjective understanding of these levels, leading to the possibility of bias in the results. For example, one educator may have assigned the answer of " 4 - supply to a high degree" to the inclusion of a 15 ECTS course in their curriculum, while another may have signed a similar value to a 5 ECTS course. The survey however intentionally ignored the measure of ECTS credits as the indicative of the supply, as the Danish Centre for Light previously attempted (Dansk Center for Lys \& Innovationsnetværket Dansk Lys, 2012). This is primarily due to the fact that the questions and answers based on ECTS may be similarly misleading, as many aspects of lighting education can be found in the courses dealing with other subjects. One example is the area of light and energy, which can fall within broader approaches and coursework on sustainability. This may have forced the respondents to make subjective estimates of the share that lighting has in the total course.

\subsection{Randomization}

To keep the order of the themes and sub-points, all the participants answered the questions in the same order. In a longer survey such as this one, where we attempted to ensure the average answer time of eight minutes, participants may become impatient, annoyed or merely bored toward the end of the survey. If so, this can cause bias in the answers to the last themes compared to the first themes. In the partially completed answers, we see that especially the 'demand' participants tended to quit the survey in the middle of theme 5 "Light and planning". This can also indicate that the participants in online surveys lose concentration after approximately 50 questions.

\subsection{Tendencies}

When comparing the results and analysis from both surveys, the demand was higher than the supply for all 111 questions. This finding might suggest a tendency that the educational suppliers were more careful in their statement of what degree they educate in the different fields, and that people on the demand side exaggerate what they need and want from the people they employ. It may however also be interpreted that there is simply a higher demand than supply in all 111 categories. However, to accommodate this apparent 
imbalance, the gap between the supply and the demand is only considered significant when the difference between the average values is above 1.25 on the scale from 1-4 (Figure 3, row 5).

Another tendency suggests that the biggest suppliers of lighting-related education are among university colleges ("professions højskoler"), although an exception to this is the theme 4 "Light \& Energy", where engineering programs supply is at a high level.

The highest demand varies over the eight themes (Figure 3, rows 11-13).

Looking at the geographical distribution of the supply based on the themes, there is a tendency towards a higher Danish supply across all themes with the exception of theme 2 "Health \& Wellbeing", where the Swedish supply is higher and theme 8 "Characteristics and Measurements", where the distribution is more even.

The country-based demand is much more inconsistent, showing a strong tendency towards a higher Swedish demand in theme 1 "Experience", theme 2 "Health \& Wellbeing" and theme 8 "Characteristics and Measurements" and a higher Danish demand in theme 4 "Light and Energy" and theme 6 "Daylight", as well as a small tendency in theme 7 "Digitalized light" (Figure 3, rows 15-16).

\subsection{Implications}

The gaps were divided into three categories based on the dominant factor responsible for the gap, i.e.: significantly low supply, higher than average demand or a combination of high demand and low supply (Figure 3, row 2). Additionally, all 111 categories were evaluated based on the gap size, statistical significance of gap and popularity. The most significant gaps were divided into three final categories that determine their priority (Figure 3, rows 3-8).

\section{CONCLUSIONS}

This study supports the findings of the previous studies, in particular the DCL-report published in 2012 (Dansk Center for Lys \& Innovationsnetværket Dansk Lys, 2012), which indicated a high demand for interdisciplinary qualifications in Denmark and pointed out that the lighting industry was lacking specialized skills related to lighting design and that many companies were willing to offer internships and collaborative projects. The research on competencies, job functions and demand in the engineering field, performed by The Danish Technological Institute, suggested that in 2020 engineers that are able to work in a cross-disciplinary field will be in high demand (Teknologisk Institut, 2013). The present study qualifies and expands this previous research, providing a more in-depth analysis of the needs for future educational programs.

The statistical analysis of the surveys highlights the significant gaps between the supply and the demand. These areas and competencies were identified and categorized. The biggest gaps were located and systemized into three categories ('high', 'some', and 'less' priority) to provide a guidance for future action.

\subsection{Primary priority}

The areas with the largest gaps between the supply of education and the employment demand, categorized as the highest priority, are as follows. In the pink category, marked as high priority, we find 18 competencies from six different topics. Of these 18, eleven topics have a large gap based on the combination of low supply (average $<2$ ) and high demand (average $>3$ ), whereas seven topics don't have a significantly high demand, but a very low level of supply (average $<2$ ). 
1.04 Landscape Planning and Light: the supply is low, with the average of 1.7 and $57 \%$ answered "not at all" and the demand is high, with $94 \%$ of the answers stating the related demand and the average of 3.1 .

2.03 Human Centric Lighting: There is an interest from the lighting industry, but the supply is very low. In total, $69 \%$ of the participants answered "not at all", while $85 \%$ require knowledge in this area, and the average is 2.9 .

3.05 Luminaire Design: a skill that can be found in design and architecture. The supply is low, as 50\% of the respondents answered "not at all", while the demand is high, with $89 \%$ of the answers stating the related demand and the average of 3.1 .

4.08 Energy Renovation: for private and public buildings and for cities. The supply is low, as $52 \%$ of the respondents answered "not at all", while the demand is high, with $93 \%$ of the answers stating the related demand and the average of 3.2.

5.02 Lighting Master Plans: zooming out and taking a view from above. The supply is low, as $74 \%$ of the respondents answered "not at all", while the demand is average, with $87 \%$ of the answers stating the related demand and the average of 2.8 .

5.03 Light Planning: in every project involving lighting design, lighting has to be planned in collaboration with architects, landscape, engineers etc. The supply is low, as $46 \%$ answered "not at all" while the demand is very high, with $97 \%$ of the answers stating the related demand and the average of 3.4.

5.04 Economy: very important in every business, but not as interesting from the research point of view. The supply is low, as 54\% answered "not at all", while the demand is high, with $95 \%$ of the answers stating the related demand and the average of 3.2 .

5.06 Urban Design and Lighting: lighting and landscape can be important for the image and growth of an area and a good opportunity to collaborate. The supply is low, as $62 \%$ answered "not at all", while the demand is high, with $92 \%$ of the answers stating the related demand and the average of 3.1 .

5.08 Tender Specifications - including lighting: being able to read and understand specifications and project requirements is not an important part of the educational curriculum at most schools. The supply is low, as $46 \%$ answered "not at all", while the related demand is very high, with $95 \%$ of the answers stating the demand and the average of 3.3 .

5.11 Public Lighting: the supply is low, as 53\% answered "not at all", while the demand is very high, with $92 \%$ of the answers stating the related demand and the average of 3.3 .

5.17 Lighting Concept Development: creativity and mastering new concepts. The supply is low, as $64 \%$ answered "not at all", while the demand is very high, with $97 \%$ of the answers stating the related demand and the average of 3.2 .

5.20 Project Planning and Light: project management and planning is a skill that many employees need to have after they graduate. The supply is low, as $52 \%$ answered "not at all", while the demand is very high, with $93 \%$ of the answers stating the related demand and the average of 3.0.

5.24 Road Lighting: Keeping up with national standards for safety and illuminance, glare etc. The supply is very low, with the average of $1.4 ; 76 \%$ answered "not at all", and the demand is average with $80 \%$ of the answers stating the related demand and the average of 2.8 .

5.25 Commissioning and Maintenance of Lighting: working in engineering companies and municipalities. The supply is very low, with the average of 1.7 and $72 \%$ answered "not at all" and the demand is average, with $86 \%$ of the answers stating the related demand and the average of 2.9 .

7.10 Smart City: understanding IoT and what the collected data can be used for is a newly required skill. The supply is very low, with the average of 1.4 and $68 \%$ answered "not at all" and the demand is average, with $79 \%$ of the answers stating the related demand and the average of 2.5 .

8.11 Evaluation of Luminaires and Light Sources: quality and post evaluation is in demand. The supply is low, as $61 \%$ answered "not at all", while the demand is very high, with $87 \%$ of the answers stating the related demand and the average of 3.1 .

8.20 Light Sources - Aging and Degradation: the supply is low and $60 \%$ answered "not at all" and the demand is average, with $89 \%$ of the answers stating the related demand and the average of 2.9 . 
8.21 Calculation Software: using a range of calculation programs to test lighting concepts and show proof of specifications in a project. The supply is low, as $66 \%$ answered "not at all" and the demand is very high, with $88 \%$ of the answers stating the related demand and the average of 3.2 .

\subsection{Further recommendations}

The study has identified the areas that require attention in order to bridge the gaps in the future. The gaps between, on the one hand, the competencies required by the employers and, on the other, the competencies provided through educational programs should be addressed through improving and expanding curricula at all levels of the educational system.

Furthermore, based on the discussions and debates in the expert interviews and focus groups carried out under this study, we further recommend that future educational curricula also take the following needs points into consideration:

- More interdisciplinary projects;

- More projects with external partners;

- Collaborations with public projects and internships at municipalities;

- The lighting industry needs more knowledge of the competencies in demand, when hiring new employees;

- Students should be aware of their opportunities in the labor market;

- Short courses for employee brush-up;

- Student "master class" in reading and understanding the required skills: standards, planning, legislation and other skills that students don't get familiar with at university;

- Economy is also an important parameter.

The above priorities are important for educational programs and institutions to note in order to move towards generating research, knowledge and graduates who can meet the rapidly changing demands within the lighting industry and related fields.

\section{Acknowledgements}

The authors wish to express their gratitude to the participants of the surveys, interviews and focus groups who took their time to engage in the study. The authors received invaluable assistance on the statistical and mathematical analyses from their Aalborg University colleagues, Associate Professor Hendrik Purwins and Research Assistant Andreas Wulff-Jensen. The study described in this paper is a part of the project 'Lighting Metropolis', financed by Interreg.

\section{References}

Dansk Center for Lys, \& Innovationsnetværket Dansk Lys. (2012). Behov for lysuddannelse $i$ Danmark. København. 
Schlangen, L. J. M., Lang, D., Novotny, P., Plischke, H., Smolders, K. C. H. J., Beersma, D. G. M., ... Halonen, L. (2014). Lighting for health and well-being in education, work places, nursing homes, domestic applications and smart cities. https://doi.org/fp7-ict-2013-11-619249 accelerate Teknologisk Institut. (2013). Den Danske ingeniør 2020 - Jobfunktioner og Kompetencekrav. Retrieved from https://www.teknologisk.dk/kompetencekrav-til-ingenioeren-i-2020/34048 